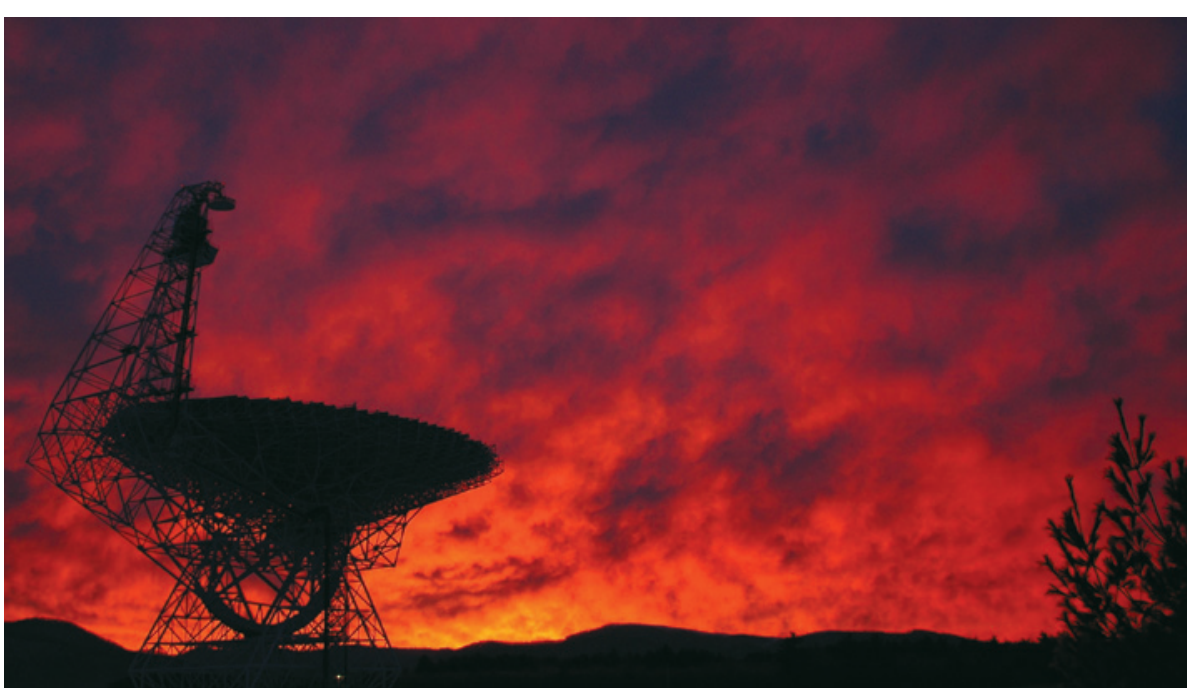

Supporters say they will fight to make sure that the Sun doesn't set on the Green Bank Telescope.

\title{
ASTRONOMY
}

\section{US telescopes face up to agency cuts}

\section{Six observatories run by the National Science Foundation should be jettisoned in favour of new facilities, says panel.}

\section{BY ERIC HAND}

$\mathrm{W}$ hen the economist Joseph Schumpeter coined the term creative destruction, he wasn't talking about telescopes. But it is a process that the US National Science Foundation (NSF) will soon be familiar with, as it seeks to shed obligations to existing astronomical observatories to make way for new ones.

On 16 August, a panel of external scientists - charged with balancing the NSF astronomy division's facilities portfolio in the face of a tougher budget climate - released its report at a meeting at the agency's headquarters in Arlington, Virginia. Its recommendations amount to a dramatic divestment of assets, including six NSF observatories, by 2017.

Four of the telescopes sit atop Kitt Peak in Arizona: the 4-metre Mayall Telescope; the 3.5-metre Wisconsin-Indiana-Yale-National Optical Astronomy Observatory (NOAO) Telescope, or WIYN; a separate 2.1-metre telescope; and the 1.6-metre McMath-Pierce Solar Telescope. The other two are radio observatories: the 110-metre Green Bank Telescope in West Virginia, the world's largest steerable dish antenna; and the Very Long Baseline Array (VLBA), a collection of ten dishes in various locations. James Ulvestad, director of the NSF's
Division of Astronomical Sciences, hopes to find new operators for the telescopes within 18 months. Only after that would the agency begin to consider closure or mothballing.

The recommendation is aimed at freeing up the US\$20 million that is currently spent on running the facilities - an amount drawn directly from the budget of the NSF astronomy division - and which creates a strain on grant programmes. "That pressure is quite real," says Daniel Eisenstein, an astronomer at Harvard University in Cambridge, Massachusetts, and chairman of the portfolio-review panel.

Another strong motivator was the need to preserve support for two future survey telescopes in Chile: the 8-metre optical Large Synoptic Survey Telescope and the Cerro Chajnantor Atacama Telescope, a 25-metre submillimetre-range telescope. "Unless you do this trimming, you can't do new things," says Michael Turner, director of the Kavli Institute for Cosmological Physics at the University of Chicago in Illinois.

But the loss of publicly funded telescopes means that it will be tougher for astronomers who are affiliated with universities that don't have access to other observatory facilities. For example, the Mayall telescope currently offers 300 nights a year of public-access time. "It's not good for the have-nots," says David Silva, director of the NOAO in Tucson, Arizona.

Silva was already in the process of courting a new partner for the Mayall telescope. The US Department of Energy is considering whether to build a special instrument, called BigBOSS, that would allow the Mayall to observe 20 million galaxies in the hunt for dark energy, which is speeding up the expansion of the Universe. BigBOSS principal investigator David Schlegel, of Lawrence Berkeley National Laboratory in California, was hoping to rally the energy department's support for the instrument while the NOAO continued to pay for operations. $\mathrm{He}$ says that if the department were to become the sole operator of the telescope, BigBOSS could complete its survey in three-and-a-half years rather than five, because the Mayall would no longer have to allocate time to other projects. Paying a few million dollars a year in operations costs would be offset by performing the survey more quickly, he says.

Silva notes that finding operators for the other telescopes on Kitt Peak will be more difficult. Small and state-funded universities are as cash-strapped as the government, he says, and private universities with deeper pockets are trying to raise money to help to fund new 30-metre-scale telescopes.

Anthony Beasley, director of the National Radio Astronomy Observatory (NRAO) in Charlottesville, Virginia, says that a move by the NSF towards total divestment could damage the NRAO's efforts to find partial support for its facilities among new partners. "They've kind of stuck a spear in our side," he says. He notes that, of the \$5.5 million in annual operating costs for the VLBA, \$2 million already comes from foreign partners. New ones may be reluctant to join if they know that the NSF wants to divest of the facility completely, he argues.

Beasley says that he is most surprised by the decision to target the recently refurbished Green Bank Telescope, which was reopened in 2000. Others doubt whether the NSF could ever shut down the observatory, which has strong support from Senator Jay Rockefeller (Democrat, West Virginia), who also chairs the Senate committee on commerce, science and transportation. In a statement, Rockefeller said: "The needs for this observatory are clear and I will work to make sure it remains open."

The portfolio-review panel worked with two budget scenarios: one in which future budgets would remain relatively flat, and another that was far gloomier, with a $20 \%$ drop by middecade from 2011 fiscal year levels. The panel recommended that the NSF should divest of the six facilities under both scenarios. Under the more optimistic scenario, it said, money saved from divestment should be used to augment research-grant budgets. Given the shortterm vagaries of the budget and the difficulties of making long-term decisions on facilities, planning for cuts is probably wise, says Turner. "Predicting budgets is harder than predicting the future of the Universe," he notes. 